\title{
SOBRE LA PERIFERIA TURDETANA Y LA CONFIGURACIÓN DIVERSA DE LA BETURIA PRERROMANAS: CÉLTICOS Y TÚRDULOS EN EL GUADIANA MEDIO
}

\author{
ON THE TURDULII PERIPHERY AND THE DIVERSE CONFIGURATION OF PRE- \\ ROMAN BAETURIA. CELTS AND TURDULOS IN THE MIDDLE GUADIANA BASIN
}

por

\author{
ALONSO RODRÍGUEZ DÍAZ
}

\begin{abstract}
RESUMEN : El objetivo principal del presente trabajo es destacar, por un lado, el carácter fronterizo del Valle Medio del Guadiana durante la Segunda Edad del Hierro y, por otro, el replanteamiento socioeconómico y cultural que permitió la superación de las consecuencias negativas que para esta zona tuvo el fin de Tartessos. Célticos y túrdulos fueron las etnias que los autores clásicos situaron en este territorio, confín septentrional de la Turdetania y a partir de ahora reconocido como Beturia, y la ganadería y la metalurgia del hierro sus pilares económicos fundamentales.
\end{abstract}

RESUME: L'objet principal de ce travail consiste à détacher le caractère de frontière de la Vallée Moyenne du Guadiana pendant la Seconde Age du Fer et aussi la récupération économique et culturelle de ce territoire-ci après la fin de Tartessos. Les «célticos» et «túrdulos» furent les peuples que les auteurs classiques ont assignés dans c'endroit-ci, confin septentrional de la «Turdetania» et à partir de ce moment identifié avec la Beturia, et les brebis et la métallurgie du fer les bases économiques principales.

En palabras de Estrabón (III, 2, 1), la Turdetania estaba regada por el río Betis y se extendía hacia el interior «por la parte de acá del Anas», cuyo curso la limitaba «al Occidente y al Septentrión». Era una tierra rica y en ella existían montes metalíferos que se prolongaban «hasta el Tágos». A pesar de su carácter tardío, estas conocidas referencias sobre la Turdetania constituyen, sin duda, una pequeña muestra de las frecuentes alusiones recogidas en las fuentes clásicas sobre este territorio y, más particularmente, sobre sus límites septentrionales. En función de ellas, podría deducirse que buena parte del actual territorio extremeño fue durante algún tiempo periferia turdetana del mismo modo que siglos atrás lo fuera de Tartessos; pero, como no es menos sabido, esos vínculos seculares entre el Guadalquivir y el Guadiana se vieron en gran medida distorsionados por la llegada a esta última zona de pueblos célticos relacionados con «los celtíberos de la Lusitania». Aunque resulta difícil precisar en el tiempo estos acontecimientos, todo parece indicar que no deben fecharse antes de finales del siglo $\mathrm{V}$ a. C. o comienzos del IV y que han 
de inscribirse en el diacrónico proceso de «celtiberización» que por entonces afectó a la mayor parte del occidente peninsular (Almagro Gorbea, 1990 y 1994). Así parecen confirmarlo las referencias a ciertas costumbres religiosas, topónimos, antropónimos, deónimos y el creciente registro arqueológico(Untermann, 1965; Albertos Firmat, 1975; Almagro y Lorrio, 1987; Rodríguez Díaz, 1989; Berrocal Rangel, 1992). En suma, a partir de entonces, en el confín septentrional de la Turdetania y más concretamente en el área comprendida entre el Guadiana y Sierra Morena, comenzaría a configurarse un nuevo espacio socieconómico y cultural, compartido por «célticos» y «túrdulos» y redefinido por los autores grecolatinos como «Baeturia» (García Iglesias, 1971).

Efectivamente, concluido el esplendor tartésico y en un contexto de reorganización global que afecta a todo el Suroeste peninsular entre los siglos IV y II a. C. (Fernández Jurado, 1987; Escacena Carrasco, 1987; Ferreira y Varela, 1992), el Valle Medio del Guadiana se nos muestra una vez más como un auténtico «espacio de frontera» en el sentido íntegro del término; es decir, como una zona relativamente habitada y próxima a otra ocupada por comunidades de tipo expansivo, como es la Meseta de los pueblos prerromanos. En este sentido y tal como acabamos de referir, podemos precisar que tanto la Arqueología como otras disciplinas (Fig. 1) coinciden en señalar durante este período la presencia de poblaciones del interior peninsular en este territorio, provocando lo que hemos dado en llamar un proceso global de «continentalización» o «celtización» del pasado orientalizante. Si bien desconocemos aún el carácter y las circunstancias que rodearon inicialmente la proyección de estos «celtici» hacia este espacio, a grandes rasgos y desde el punto de vista cultural, dicho proceso -sin llegar a ignorar la tradición-individualizará, que no aislará, a la actual región extremeña de las grandes áreas de la Cultura Ibérica y de Andalucía Occidental (Domínguez Monedero, 1983; AA.VV., 1987-1). Al sur del Guadiana, célticos y túrdulos (o turdetanos) serán, junto a los vettones del Tajo Medio, los protagonistas principales de un horizonte de incuestionable personalidad, cuyos restos materiales revelan de nuevo que nos encontramos ante una «cultura de frontera» surgida del contacto entre el centro y la periferia peninsular.

Pero aparte del agotamiento del «modelo orientalizante» en nuestra región a parir de la crisis del 400 a. C. (Maluquer de Motes, 1981; Rodríguez Díaz, e. p. ), actualmente consideramos (y así lo trataremos de argumentar a lo largo del presente trabajo) que las claves económicas que subyacen en el reajuste cultural de este territorio podrían concretarse en la búsqueda por parte de las citadas poblaciones meseteñas de materias primas como el hierro y la necesidad de pastos para el ganado durante los rigurosos inviernos de la Meseta. Por tanto, hierro y ganado, pilares básicos del poder y del prestigio de las élites y pobladores de las tierras interiores de la Península, parecen ser también los factores condicionantes principales de su proyección hacia el Sur y, más concretamente de su establecimiento en la Cuenca Media del Guadiana, aprovechando el vacío y la incertidumbre generada por el fin de la hegemonía tartésica.

Como veremos más adelante, uno de los aspectos que hoy mejor refleja el replanteamiento socioeconómico y cultural de esta etapa de la «protohistoria extremeña» es el poblamiento. Podemos anticipar sobre esta cuestión que las diversas actuaciones arqueológicas llevadas a cabo durante la última década están revelando el surgimiento de un nuevo patrón de asentamiento que tiene como célula básica «el castro». En concreto, se trata de lugares estratégicos y de buenas condiciones defensivas que -salvo en aquellos casos de paso obligado (vados del Guadiana)-no estuvieron habitados en etapas inmeditamente anteriores, si bien con cierta frecuencia se están detectando ocupaciones calcolíticas. En función de ello, todo parece apuntar hacia una importante reorganización territorial respecto al Período Orientalizante que, como es lógico, implica el desarrollo de una nueva estrategia de control sobre el espacio y sus recursos potenciales. Dicha estrategia, como ya hemos comentado, parecer ser que no es otra que la promueven la ganadería y la metalurgia del hierro y en ella parece fundamentarse cada vez en mayor grado la configuración plena y diversa de la Beturia (Fig. 2). 
Pero dentro de este nuevo panorama que a partir del crítico 400 a. C. se desencadena en la Cuenca Media del Guadiana, estamos prácticamente convencidos de la existencia de notables diferencias interregionales; diferencias más que probablemente ligadas a una desigual intensidad del referido proceso de «celtización» que por estas fechas afecta a esta zona y a una menos desigual perduración del sustrato orientalizante. Aunque el estado actual de la investigación no siempre lo permite, somos conscientes de que asumir el reto que conlleva contrastar paulatinamente dicha hipótesis nos obliga a contemplar siempre un análisis interrelacionado de aspectos geográficos, literarios, tecnológicos, sociales, económicos, lingüísticos e ideológicos. De hecho, este planteamiento ha empezado ya a dar sus primeros frutos y, al tiempo que nos está descubriendo un horizonte cultural cuyo rasgo más definidor es la convivencia de elementos meseteños y meridionales combinados con una tradición orientalizante cada vez más desdibujada y reinterpretada, comienza a ofrecernos testimonios evidentes de su diversidad. La explicación de todo ello cada vez más parece encontrar el mejor argumento de fondo en la identificación diferenciada que los autores clásicos hicieron de este territorio: la «Beturia Céltica» y la «Beturia Túrdula».

\section{LA BETURia CÉLtica}

El actual territorio extremeño integrado en la «Beturia Céltica» se corresponde básicamente con la mitad occidental de la provincia de Badajoz (comarcas de Jerez de los Caballeros-Segura de León, Olivenza y Zafra), si bien dicho ambiente cultural se prolonga claramente hacia la serranía onubense y el Alentejo (García Iglesias, 1971; Del Amo, 1978; Maia, 1985; Pérez Macías, 1990; Berrocal Rangel, 1992), y hasta las fuentes se hacen eco de una controvertida y poco probable existencia de núcleos célticos en pleno Valle del Guadalquivir. En principio, es Plinio (III, 13-14) quien refiere que «la comarca que se extiende más allá de la que limita el Baetis (...), y que llega hasta el Anas, se llama Baeturia y se divide en dos partes y en otras tantas gentes: los celtici, que lindan con la Lusitania y que pertenecen al Conventus Hispalensis, y los turduli, que limitan con la Lusitania y la Tarraconense, pero que dependen de la jurisdicción de Corduba. Los celtici venidos de la Lusitania son oriundos de los celtiberi, y ello se manifiesta por los ritos religiosos, por la lengua y los nombres de los «oppida», que en la Baetica se distinguen por sus cognombres: Seria, llamada Fama Iulia; Nertóbriga, dicha Concordia Iulia; Contributa, cognominada Iulia Ugultunia, ahora también Curiga; Lacimurga, llamada Constantia Iulia (...) Además, en la Céltica, se hallan Acinippo, Arunda, Arunci, Turóbriga, Lastigi, Salpesa, Saepone, Serippo» (García y Bellido, 1947: 127).

Con las reservas lógicas que impone la cronolog;ía avanzada de los textos,una primera valoración del poblamiento prerromano de este sector de la Beturia pone de manifiesto su estrecha relación con el control del frondoso paisaje de dehesa que integran las cuencas fluviales del Ardila, Alcarrache o el propio Guadiana y, sobre todo, con la explotación de los principales filones férricos que caracterizan el subsuelo del suroeste badajocense (AA. VV., 1987-2; Rodríguez Díaz, 1989 y 1990; Canto, e.p.). Aunque aún no contamos con una valoración arqueometalúrgica de esta zona y por ende no haya podido determinarse la explotación protohistórica de estos yacimientos, la proximidad entre dichos filones metalíferos y los castros de este área junto a los testimonios arqueológicos recuperados parecen evidenciar -como concretaremos más adelante- un alto grado de especialización de estas comunidades en la explotación y difusión del hierro. En este sentido, son de referencia obligada los poblados de la Sierra de la Martela de Segura de León (Enríquez y Rodríguez, 1988), Los Castillejos de Fuente de Cantos (Fernández y otros, 1988), la Sierra del Coto de Fregenal de la Sierra (Nertóbriga), Castillo de Jerez (Carrasco Martín, 1991) la Ermita de Belén de Zafra (Rodríguez Díaz, 1991a), Capote de Higuera la Real (Berrocal Rangel, 1988 
y 1989b) y, ya en territorio portugués y al otro lado del Guadiana, el castro de Segovia (Júdice Gamito, 1981). (Fig. 2, núms. 2, 1, 44, 49, 4, 47 y 50).

Dichos poblados se sitúan en lugares elevados, de perfil amesetado y sus estratigrafías normalmente no remontan el siglo IV a. C. ni tampoco suelen exceder el siglo I de la Era. Su desarrollo urbanístico y sistemas de defensa generan núcleos de población poco extensos que giran en torno a 1 ó $3 \mathrm{Ha}$. de superficie máxima, aunque existen algunas excepciones que superan las $4 \mathrm{Ha}$. (Nertóbriga). Las construcciones defensivas mejor representadas son las murallas, que con un trazado irregular y en número de dos o tres protegen los flancos más vulnerables de estos poblados. En algunos casos concretos, se ha podido determinar que la estructura de dichos recintos se compone indistintamente de un doble paramento con relleno interior, casamatas (Los Castillejos de Fuente de Cantos) o un potente muro ataludado y aparejo careado al exterior (La Ermita de Belén, Nertóbriga y Capote). También de forma muy puntual se conoce la existencia de fosos, terraplenes y piedras hincadas que complementan el potencial defensivo de estos recintos amurallados.

La organización interna de estos asentamientos parece obedecer a un plan previo, según se desprende de la orientación uniforme de las construcciones domésticas hasta el momento conocidas. Además de las grandes estancias rectangulares y «ceniceros» documentados hace ya algún tiempo en Los Castillejos de Fuente de Cantos o el basurero intramuros excavado en la Ermita de Belén (Rodríguez Díaz, 1989 y 1991a), sin duda el caso mejor conocido hasta ahora es el del Castrejón de Capote. Recientemente, ha sido dado a conocer un sector de este extenso poblado en el que a partir de una «calle central» se delimitan dos manzanas de viviendas configuradas por estancias rectangulares de dimensiones variables. En algunas de ellas, se aprecia la existencia de bancos corridos, hogares de arcilla y pies de postes como principales elementos de arquitectura doméstica. Entre dichas estancias, se encuentra la denominada por su excavador «Santuario o Altar A» basándose en el gran volumen cerámico amortizado en todo su interior y sobre un pequeño poyete central junto a restos óseos, cenizas y diversos objetos metálicos (Berrocal Rangel, 1989b). Sin entrar en la valoración concreta de este espectacular hallazgo, especial interés ofrece, por cuanto pueda reportar al estudio de las relaciones culturales de esta zona, la planimetría general de estas estructuras de habitación que, en su conjunto y a través de sus distintas fases, muestra, como el propio autor ha señalado, evidentes semejanzas con los poblados protohistóricos del Valle del Ebro (Berrocal Rangel, 1989b; Blasco Bosqued, 1987 y 1989).

De entre las diversas estructuras integradas en las construcciones domésticas de estos poblados célticos, mención especial merecen algunos hornos y subestructuras relacionadas directamente con la manipulación del hierro. En este sentido y aparte de la abundancia de escorias recuperadas, los mejores ejemplos los han proporcionado los hornos de base en hoyo, de poco más de $30 \mathrm{~cm}$. de diámetro, documentados hace ya algunos años en el poblado de Los Castillejos de Fuente de Cantos (Rodríguez Díaz, 1989); y, más recientemente, el espacio-taller o fragua aparecido en el también referido poblado de Belén (Zafra). El elemento más definidor de éste era una pequeña estructura de adobe, de algo más de $1 \mathrm{~m}$. de longitud y completamente repleta de escorias y cenizas, que fácilmente puede corresponderse con un horno con basamento de adobe. En función del contexto y entidad de estas manifestaciones arqueológicas, desde siempre hemos valorado estos hallazgos como pruebas de una actividad metalúrgica de carácter familiar integrada en una producción a mayor escala, de la que a nuestro juicio constituye un fiel reflejo la enorme concentración de poblados en este área filoniana (Rodríguez Díaz, 1990). Precisamente, éstos junto a otros argumentos son los que han llevado a A. Canto, en un trabajo áun inédito, a considerar esta zona como una auténtica «Beturia Férrica» (Canto, e.p.) durante época romana.

Pero aparte de la actividad minero-metalúrgica de los poblados célticos de la Cuenca Media del Guadiana, resulta obligado referir el enorme potencial agroganadero que atesora el paisaje de dehesa que 
les rodea. Del período que nos ocupa ya se poseen informes faunísticos de Capote, Los Castillejos de Fuente de Cantos y la Ermita de Belén (Castaños Ugarte, 1987 y 1991 a y b). Una valoración conjunta de dichos estudios nos pone en relación directa con poblaciones con un régimen de subsistencia animal de tipo mixto en el que ovicaprinos, bóvidos, suidos y équidos - por este orden-constituyen la base de la fauna domesticada y el ciervo es con diferencia el animal más cazado. En este mismo sentido, podemos concretar que ese carácter principal de la ganadería ovicaprina, aparte de constituir uno de los rasgos más definidores de las comunidades pastoriles del mundo prerromano peninsular, es, a la vez, uno de los aspectos diferenciadores más relevantes respecto al Período Orientalizante en la explotación de especies domésticas en todo el Suroeste (Almagro Gorbea, 1983) (Gráf. 1). No hemos de olvidar tampoco que ovejas, cabras y bóvidos son las especies que mejor se adaptan al extremado clima y al paisaje de esta zona, si bien también otros factores de tipo ideológico pudieron estimular su desarrollo. Lógicamente nos referimos a la presencia de restos de ovicápridos formando parte de ofrendas o ágapes rituales en el ya citado «Santuario A» de Capote y -ya fuera de este ámbito «estrictamente céltico»- en las necrópolis de Medellín y Hornachuelos. Además, en este mismo sentido, resulta de referencia obligada el conjunto de bronces votivos íbero-romanos (Blázquez Martínez, 1962; Alvarez S. de Buruaga, 1970; Maluquer de Motes, 1981) e inscripciones (Balmori, 1935; López Melero, 1986; Caballero y Rosco, 1988) relacionadas o dedicadas a Ataecina que salpican la geografía extremeña y que precisamente tienen como modelo iconográfico la cabra.

Dicho todo esto es fácil deducir que la agricultura debió tener un carácter secundario en la estructuración económica de estas poblaciones. No obstante, su desarrollo está documentado a través de aperos de labranza (hoces, podaderas, azuelas, molinos y molederas) junto a restos de cereales carbonizados que confirman la explotación de las vegas o las tierras de labor inmediatas. En este mismo sentido, no faltan espacios dedicados a la molturación o al almacenaje de excedentes dentro del parcial conocimiento que hoy se posee sobre la funcionalidad de las estancias que configuran las viviendas de estos poblados.

Si éstas fueron las directrices básicas que rigieron la vida de las comunidades célticas del Guadiana Medio, mucho menos conocidas resultan sus pautas de comportamiento ante la muerte y la religión. Aunque en los últimos años trabajos diversos están permitiendo localizar numerosos hallazgos posiblemente relacionados con espacios funerarios, todavía ninguno de ellos ha sido objeto de excavación. Entre dichos descubrimientos, destaca el del Cantamento de la Pepina, en plena cuenca del Ardila y dentro del término municipal de Fregenal de la Sierra (Rodríguez y Berrocal, 1988; Berrocal Rangel, 1990). De un lugar muy próximo al poblado y tras la actuación reiterada de varios clandestinos, recogimos abundante material cerámico decorado, asociado a primera vista a lentejones de cenizas, restos óseos indeterminados y desdibujados empedrados tumulares. En su conjunto, todos estos elementos parecen estar en clara relación con los recuperados en torno a los años 50 por A. Viana y A. Dias (1950) en las denominadas por ellos mismos «necrópolis céltico-romanas» del concejo de Elvas, donde -como se recordará- en el lugar de Herdade de Chaminé dichos autores refieren la existencia de estructuras tumulares de planta diversa junto a sepulturas en hoyo entre cuyo ajuar destacan numerosas vasijas cerámicas modeladas y una espada de antenas atrofiadas.

También de un contexto funerario proceden los restos cerámicos recientemente recuperados por algunos aficionados en los alrededores de Lobón'. Concretamente se trata de una urna y un plato con decoración pintada que contenía numerosos restos cremados que afortunamente pudieron recuperarse y en la actualidad están en estudio (Fig. 4 y Fig. 2, núm. 51). Desde el punto de vista tipológico, la urna

1. Agradecemos esta información al arqueológo de la DGPC de la Junta de Extremadura, Dr. Juan-Javier Enríquez Navascués. Los materiales se encuentan depositados en el MAP de Badajoz. 
muestra un cuello medianamente desarrollado, cuerpo bitronconónico y base con leve pie indicado. La decoración se concentra en la mitad superior de la pieza y consiste en bandas pintadas de anchura variable combinadas con una serie de sectores de círculos concéntricos que ocupan la parte central de la vasija. El color utilizado es exclusivamente el rojo vinoso con tonalidades violáceas. Morfológicamente, dicho recipiente podría formar parte del perfil XVIII-A y de la variante B del Grupo Formal 4, establecidas respectivamente por Escacena (1986) y Pereira (1988) en sus estudios sobre las cerámicas pintadas en Andalucía. Para el primero, la distribución de este tipo cerámico se constata casi exclusivamente en el Alto Guadalquivir y su procedencia podría estar vinculada a determinados estímulos septentrionales que afectaron Andalucía Occidental en torno al siglo III a. C. Por su parte, Pereira confirma que desde el siglo VI a. C. , y en particular a partir del siglo IV a. C., este grupo de vasos se documenta por toda la Cuenca del Guadalquivir (Cerro Macareno, Toya, Alcalá del Río, Osuna, Carmona, Ceal, Baza, etc.) Asímismo, precisa que los ejemplares fechados entre los siglos IV y III a. C. aparecen especialmente concentrados en el sector occidental de Andalucía (Pajar de Artillo, Cerro Macareno, Alhonoz y más recientemente Gilena) (Pereira, 1988: 152; Belén y Escacena, 1992: 512, fig. 3 núm. 5). El recipiente menor asociado a la urna se corresponde con un plato de borde vuelto y fondo plano, decorado en su totalidad a excepción del fondo interno/externo con engobe rojo de baja calidad. Dicha pieza parece identificarse con la Forma A3/4 de Cuadrado (1953), documentada en contextos crono-culturales diversos en Levante (Cuadrado de Isasa, 1970; García e Iniesta, 1982), Andalucía -necrópolis de Los Patos y Almedinilla- (Blázquez Martínez, 1975; Vaquerizo Gil, 1988-89) y otros yacimientos interiores -Alarcos- (Fernández Rodríguez, 1987: fig. 27). Aunque tipológicamente resulta fácil vincular estos hallazgos con probables importaciones del sur y sureste peninsular, mucho más complejo sería proponer una cronología concreta para los mismos sin una intervención arqueológica previa. No obstante, entendemos que dicha datación no debe estar muy alejada del siglo III a. C. o, en cualquier caso, no superar la segunda mitad del IV.

A todas luces, resulta evidente que extraer conclusiones o inferencias sobre la estructura social dominante entre estas comunidades célticas del Guadiana Medio hoy por hoy resultaría tan arriesgado como inapropiado, aunque según se infiere de otros testimonios parece clara su configuración gentilicia. Por otra parte y al margen de manifestaciones más o menos dudosas o probables, la religiosidad de estas comunidades podría haber encontrado su mejor testimonio en la excavación del ya citado «Santuario A» de Capote. Aunque aún no contamos con una publicación detallada de dicho hallazgo, todo parece indicar que los ritos celebrados en este lugar, de clara filiación atlántica, están vinculados al ciclo solar y sin duda debieron constituir el mayor factor de cohesión e identidad cultural de estos célticos de la Beturia (Berrocal Rangel, 1992).

Una última valoración sobre de los restos materiales recuperados hasta el momento en este ámbito del Valle Medio del Guadiana revela una vez más el rasgo cultural dominante durante la protohistoria reciente en toda la región extremeña: la coexistencia de elementos meseteños y meridionales combinados con una eclipsada tradición orientalizante. No obstante, dentro de este panorama cultural general, los hallazgos de la mitad occidental de la actual provincia badajocense muestran una serie de particularismos que la diferencian del área túrdulo-turdetana y por ende de la vettona. En este sentido, especial protagonismo tiene el nutrido grupo de cerámicas modeladas, lisas o decoradas con motivos inciso-impresos, aplicados y estampillados. Con pastas de muy diversa calidad y acabado, se realizaron escudillas de perfil troncocónico, cuencos semiesféricos, vasos de paredes entrantes, de perfil en $\mathrm{S}$ y globular y, como grupo independiente, los vasos calados o «quemadores». A distinta altura pero siempre en la superficie externa de estos recipientes se desarrollaron ziz-zags, pequeñas impresiones, triángulos, espigas, impresiones a peine o a punta de navaja, ungulaciones, cordones aplicados e incluso pequeños motivos estampillados realizados con matrices muy simples (Fig. 3). Sin infravalorar los resabios cogoteños de estos materiales, 
que encuentran su mejor representación en los poblados de Belén y Capote y en el posible complejo funerario de Fregenal de la Sierra, sus paralelismos morfológicos y decorativos más próximos nos llevan al sur de Portugal, y más concretamente al depósito votivo de Garvao (Beirao y otros, 1985), inscrito en el llamado Ferro II Continental y coetáneo de Cogotas II. Se trata de materiales que carecen de antecedentes inmediatos en nuestra región y, en general en el Suroeste, pero que, sin embargo, derivan de las principales tradiciones cerámicas de la Meseta y del Valle del Ebro (Castiella Rodríguez, 1977) que se revitalizaron con especial fuerza y entidad durante el Hierro II en el Alto y Medio Duero (Wattenberg, 1963: láms. IIIV; Abásolo Alvarez y Ruiz Vélez, 1979; Abásolo y otros, 1983; Barrio Martín, 1988: 402; Sacristán, 1986, etc.) La posibilidad de contactos entre zonas tan alejadas entre sí, a la luz de los testimonios escritos, no resulta en absoluto descabellada si se tiene en cuenta que los vacceos y celtíberos se expandieron hacia el Sur a costa de los vettones con el propósito de controlar parte de las tierras ganaderas situadas al sur del Duero. Esta referencia no haría más que fortalecer la hipótesis de una procedencia diversa de los pueblos «celtíberos» que, aprovechando el fin de la supremacía tartésica, se proyectaron a partir del siglo V-IV a. C. hacia el Sur dando origen y desarrollo a la Beturia.

Sin embargo, la continuidad y fluidez de los contactos seculares entre esta zona y el sur peninsular se confirman través de especies cerámicas como la decorada con motivos geométricos pintados (Escacena Carrasco, 1986; Pereira, 1988 y 1989) y de barniz rojo tardío (Cuadrado Díaz, 1969), que, en mayor o menor medida, forman parte de los conjuntos vasculares de los poblados de este sector extremeño. Sin duda, uno de los más recientes ejemplos de dichos contactos son los ya mencionados hallazgos cerámicos procedentes del posible contexto funerario de Lobón. Aunque de forma esporádica, las relaciones con el Mundo Ibérico también se constatan a través de hallazgos de piezas metálicas de armamento o de uso doméstico, como la falcata y cuchillos procedentes del castro de Capote (Berrocal Rangel, 1989b). Asímismo, las importaciones áticas son muy escasas. Por su parte el pasado orientalizante también queda especialmente plasmado en la tecnología cerámica representada por la especie gris, pero sobre todo será en la orfebrería donde mejor se aprecian esos vínculos con la tradición. Respecto a la cerámica, justo es reconocer la evolución formal experimentada en el repertorio tipológico de este grupo (vasos de perfil en $S$ y cuencos esencialmente). Pero quizá el rasgo evolutivo más definidor de estas cerámicas sea la presencia de motivos decorativos estampillados de claro «sabor portugués» (escudetes, reticulados, aspas, troquelados, etc.) (Arnaud e Júdice, 1974-77) que, de algún modo, se hacen eco de las modas culturales dominantes en esta zona durante estos momentos (Hernández Carretero, 1993). Pero, como quedó dicho, es posiblemente en la orfebrería donde mejor se plasman esos contactos permanentes entre el pasado y el presente, a través del surgimiento de una iconografía de clara raigambre céltica desarrollada con unos convencionalismos técnicos orientalizantes que encuentran su mejor expresión en las placas de Segura de León (Enríquez y Rodríguez, 1985; Berrocal Rangel, 1989a).

En conclusión y a modo de resumen, podemos concretar que la información acumulada hasta ahora sobre la «Beturia Céltica» durante época prerromana nos pone en relación con un espacio muy poblado, homogéneo y con un claro carácter emergente entre los siglos IV y II a. C. Aunque aún desconocemos el carácter real que dominó la llegada de estos célticos, esta zona debió constituirse en poco tiempo en un foco particularmente atractivo para las poblaciones del Guadiana Medio u otras áreas periféricas, al convertirse (quizá sin pretenderlo) en una auténtica alternativa de recuperación socioeconómica tras el fin de la hegemonía tartésica. De ser así, es fácil deducir que en el seno de estos nuevos asentamientos especializados en la explotación del hierro y de los variados recursos de la dehesa debieron generarse importantes imbricaciones culturales que podrían explicar muy bien la toponimia de muchos de ellos, la antroponimia o la coexistencia de elementos tecnólógicos de tan diversa filiación. Sin duda, son todos ellos aspectos que en mayor o menor grado fundamentan la personalidad arqueológica de este ámbito fronterizo y, por tanto, 
de confluencia cultural. En este sentido, consideramos oportuno recordar la cita de Estrabón (III, 2, 15) en la que al referirse a la bondad de las relaciones entre los «nuevos celtas» y los «turdetanos primitivos» escribe: «Éstos (los turdetanos) poseen costumbres dulces y cultivadas, debido a su vecindad con los keltikoí, o como ha dicho Polybios, a su parentesco» (García y Bellido, 1945: 106).

El contacto con el mundo romano de estas comunidades, según se desprende de los testimonios escritos y de los propios restos arqueológicos, debió ser bastante traumático. Las diversas fases constructivas asociadas a niveles de incendio y destrucción registradas en estos asentamientos parecen tener como claro telón de fondo los conflictos lusitanos y civiles. Sin embargo, una vez superadas estas primeras etapas y consolidado el dominio romano merced a «la política integradora» de César en esta zona, la arqueología evidencia que la mayor parte de estos poblados potenció su estructura socioeconómica tradicional: la metalurgia del hierro y la ganadería ovicaprina y bovina. No sería hasta fines del siglo I de la Era cuando, en el sobradamente conocido y renovado marco de relaciones sociopolíticas que define esta etapa, comenzó la profunda renovación de dicho sistema económico y la mayor parte de estos asentamientos se abandonó de un modo definitivo para emprender una sistemática explotación de los feraces llanos y terrenos aluviales de esta zona. Muy pocos -como Nertóbriga- alcanzarían un papel relevante en la reorganización administrativa romana de este territorio.

\section{LA BETURIA TÚRDULA}

En los límites septentrionales de la Turdetania Polibio situó a los «túrdulos» cuyas diferencias con los «turdetanos» Estrabón (III, 1, 6) no alcanzó a distinguir: «Dicha región se llama Baitiké, del nombre del río, y Tourdetanía, del nombre del pueblo que la habita; a estos habitantes llámaseles tourdetanoí y tourdoúloi, que unos creen son los mismos; mas según otros, dos pueblos distintos. Polybios está entre éstos últimos, pues dice que los tourdetanoí tenían como vecinos por su Norte a los tourdoúloi. Hoy día no se aprecia ninguna diferencia entre ambos pueblos» (García y Bellido, 1945: 60). Aunque desde el punto de vista lingüístico estas diferencias se valoran actualmente como «la adecuación al léxico y morfología latinos de una pronunciación puramente indígena» (García Moreno, 1989: 290), parece evidente la existencia de diferencias culturales entre el centro y la periferia turdetana que igualmente podrían justificar la distinción contemplada en los textos (v. infra). Morfológicamente este sector túrdulo de la Beturia se vertebra en amplios espacios con una dirección dominante NW-SE, que en sí mismos constituyen auténticos corredores naturales determinados en gran parte por los ríos Zújar, Ortigas, Guadámez y Matachel. En esta zona, que acabaría perteneciendo al Conventus Cordubensis, Plinio (III, 15) menciona una serie de «oppida» no sin fama: Arsa, Mellaria, Mirobriga, Regina, Sosingi, Sisapon» (García y Bellido, 1947: 128).

En líneas generales, se trata de un territorio con una vocación preferentemente ganadera y con un potencial en galenas argentíferas muy considerable, a pesar del carácter hostil y árido de algunas zonas concretas. En este sentido, resulta obligado subrayar la prolongación natural de este espacio hacia los focos mineros de Almadén (Fernández y Caballero, 1988) y del norte Córdoba (López Palomo, 1987; Murillo Redondo, 1993). Sobre este aspecto concreto, no está de más recoger la referencia de Estrabón (III, 2, 3) sobre «las comarcas donde hay metales». Éstas, según este autor, «son por naturaleza ásperas y estériles; así son también las contiguas a la Karpetanía, y aún más las que confinan con los keltíberes. Tal es, igualmente, el aspecto de la Baitouría, cuyas secas llanuras bordean el curso del Anas» (García y Bellido, 1945: 74).

Consideramos precisamente que estos aspectos -los pastos, el plomo argentífero y muy especialmente 
su fisiografía caminera- fueron aspectos condicionantes de primer orden en la organización territorial de esta zona durante toda la protohistoria. Concretamente, durante época prerromana, la mayor concentración de asentamientos se observa en lo que podríamos considerar límites de este territorio: los valles del ZújarGuadiana y Matachel. Entrerríos (Almagro Gorbea y Lorrio, 1986), Magacela, Medellín (Almagro Gorbea, 1977), El Casarón de La Coronada, Cogolludo, Los Vadillos de Esparragosa de Lares, Las Poyatas de Zarza Capilla, Tabla de las Cañas (Domínguez y García, 1991), Peñón del Pez, Las Dehesillas (Rodríguez e Iñesta, 1984), el Castillo de Bienvenida (Rodríguez Díaz, 1987), Alange (Enríquez Navascués, 1988) y quizá Hornachuelos (Rodríguez Díaz, 1991b) constituyen los ejemplos más relevantes de este sector del Guadiana Medio (Fig. 2, núm. 12, 14, 48, 25, 20, 23, 24, 41, 40, 26 y 3). Una primera aproximación al poblamiento de este área muestra una clara tendencia a ocupar enclaves destacados, de extensión variable (entre 1 y $7 \mathrm{Ha}$.) y gran valor estratégico por su amplio dominio visual del entorno o por su proximidad a los principales vados o pasos de este eje Guadiana-Guadalquivir. En función precisamente de esto último haya que explicar quizá la constatación en no pocos casos de ocupaciones ininterrumpidas desde el Bronce Final a época medieval (Medellín), si bien en otros puntos trabajos diversos han documentado estratigrafías centradas exclusivamente entre el siglo IV a. C. y el Alto Imperio (Tabla de las Cañas). De la estructura defensiva de estos hábitats se reconocen en superficie dos o tres recintos amurallados y de sus viviendas sabemos muy poco aún. También en superficie se advierte a veces la presencia de grandes aljibes excavados en la roca. Como rasgo destacable, señalar la existencia probable de pequeños peñones fortificados y posibles caseríos agrícolas localizados en las proximidades de los enclaves de mayor entidad (Rodríguez y Ortiz, 1990).

Asímismo, hemos de reconocer que la estructura socioeconómica de los asentamientos túrdulos detectados hasta el momento resulta muy parcialmente conocida. En este sentido y sin ignorar las limitaciones de la denominada «Arqueología del Territorio», las valoraciones teóricas dirigidas a la evaluación de los recursos potenciales del espacio inmediato a los poblados (Rodríguez Díaz, 1987; Jiménez Avila, 1990) muestran un claro predominio de los pastizales respecto a los espacios susceptibles de ser cultivados. Igualmente, se carece aún de muestreos óseos amplios inscritos en contextos claramente prerromanos que nos informen sobre los criterios dominantes en la explotación y manipulación de las especies animales hasta ahora reconocidas: oveja-cabra, buey y ciervo. Sin duda, el mejor complemento de todo ello debió ser una vez más el cultivo de los terrenos aluviales inmediatos a los poblados y, sobre todo, la explotación de los recursos minero-metalúrgicos del subsuelo de esta zona. A las frecuentes mineralizaciones de hierro que afloran por toda la región, hay que sumar el gran potencial de galenas argentíferas del eje Azuaga-Castuera, cuya explotación y beneficio de plomo-plata se constatan de un modo especialmente intenso a partir de época republicana.

Si parcialmente conocidas resultan aún estas cuestiones, mucho más aún lo son las relativas a la muerte y la religión. Aunque se conocen varios puntos en los que en los últimos años se han producido hallazgos relacionables con cementerios (Los Vadillos y Peñón del Pez), la aproximación al mundo funerario de este ámbito continuamos haciéndola a partir de la necrópolis republicana de Hornachuelos. A pesar de su carácter tardío, dicha necrópolis parece plasmar el reflejo de los ritos funerarios tradicionales de esta zona en función de los tipos de tumbas y ajuares documentados hasta ahora. En líneas generales, se trata de un conjunto funerario en el que domina claramente la cremación de los cadáveres y en el que el aspecto más relevante es la delimitación de diversos círculos funerarios, definidos en torno a grandes construcciones tumulares de planta rectangular, cuadrada o circular. Los tipos de tumbas establecidos hasta el momento son tres: en hoyo, «in situ» y en urna, que son las más abundantes. Globalmente, las referidas construcciones tumulares agrupan en torno a ellas 45 de los 60 enterramientos excavados hasta 1991 y sus siempre escasos ajuares reportan una cronología aproximada entre el siglo II a. C. y el cambio de Era. Es 
precisamente en dichas agrupaciones funerarias donde quizá mejor parecen quedar reflejados los rasgos de las fórmulas de carácter suprafamiliar que debieron regir la organización social de estas gentes también durante los siglos precedentes a la conquista romana (Fig. 5).

Pero dada la extraña y controvertida ausencia de necrópolis en la Turdetania (Escacena Carrasco, 1989), estos hallazgos bajoextremeños plantean serios problemas interpretativos. Tal como hemos expuesto en un reciente trabajo presentado al Congreso sobre Necrópolis Ibéricas (Rodríguez y Enríquez, 1992), la solución de éstos pasa de forma obligada por la valoración interrelacionada de diversas cuestiones entre las que destacamos particularmente tres: 1) la valoración del pasado orientalizante y sus pervivencias posibles; 2) el análisis de las interacciones culturales que caracterizan el Hierro II en este espacio geográfico; y 3) los acontecimientos sociopolíticos republicanos que tan directamente incidieron en esta zona y, más concretamente, en este yacimiento. Por su parte, las consideraciones sobre las creencias religiosas de estos grupos no pueden de momento ir más allá de la constatación a través de testimonios igualmente tardíos del culto a Adaegina Turobriguense (López Melero, 1986), a Sucellus (Blázquez Martínez, 1983; Vaquerizo Gil, 1986) y los ceremoniales del aún inédito santuario de raíces indígenas de la Cueva del Valle (Alvarez Martínez, 1985). Aunque excesivamente fragmentarios, dichos testimonios confirman el arraigo en este territorio de tradiciones religiosas de raigambre céltica que, sin duda, han de valorarse en el contexto global de la formación de la Beturia. Finalmente y a partir de época bárquida, parece constatarse en esta zona un notable resurgir de algunas divinidades orientales (Melkart y Tanit), según se desprende de los estudios numismáticos realizados por M. P. García y Bellido (1991).

Todos estos aspectos en buena medida parecen subrayarse a través de la cultura material recuperada en los poblados y necrópolis de esta zona (Fig. 6). Sin faltar la cerámica modelada, la producción vascular mayoritariamente está realizada a torno y su calidad resulta bastante desigual. Predominan las cerámicas de cocción oxidante, cuyo aspecto exterior oscila entre el anaranjado y el rojo oscuro. Las formas más habituales se corresponden con vasijas de gran tamaño y formas de medianas proporciones entre las que destacan las urnas de borde vuelto, los vasos de perfil en $\mathrm{S}$, los cuencos de cuerpo semiesférico y los platos de borde saliente de tradición orientalizante. En su mayoría, son recipientes que carecen de decoración, si bien en porcentaje variable y en función de la cronología más o menos avanzada de los yacimientos muestran motivos estampillados de clara fialiación cogoteña (pequeñas rosetas, aspas, troquelados, reticulados, series de SSS, etc.) o los geometrismos pintados tan definidores del Guadalquivir. En relación con esta especie cerámica, hemos de referirnos una vez más al cada vez mayor número de perfiles típicamente ibéricos y hallazgos de barniz rojo tardío que aparecen formando parte de los conjuntos vasculares de esta zona y que confirman la existencia de contactos entre la Cuenca Media del Guadiana y el Sureste peninsular. A dichos contactos, que preferentemente debieron realizarse a través del Guadalquivir, también cabría atribuir el peine tipo Serreta de Medellín y la figura del «Sileno de Capilla» (Olmos Romera, 1977). No obstante, la presencia en algunos yacimientos bajoextremeños de cerámicas jaspeadas (Domínguez y García, 1991) y otras que combinan la decoración pintada y la estampillada obliga a tener muy en cuenta en este mismo sentido la ruta de la Meseta Sur (Almagro Gorbea, 1976-78). Por su parte, la cerámica gris mantiene en líneas generales su buena calidad técnica, aunque su repertorio formal, compuesto básicamente por vasos de perfil en $\mathrm{S}$ y cuencos hemiesféricos, dista bastante de los perfiles que siglos antes se produjeron en este mismo territorio (Lorrio Alvarado, 1988-89). Pero, dentro de la consideración de las tradiciones tecnológicas orientalizantes de esta zona, es una vez más la orfebrería la que, a través de pequeñas arracadas y otros objetos de adorno que dignifican de una forma mesurada los ajuares de algunas tumbas, constituye la mejor expresión del declive y la reinterpretación del pasado inmediato de esta zona. En este mismo sentido, valoramos también el creciente número de fíbulas anulares $y$, sobre todo, de La Tène recuperadas en estos yacimientos y que concuerdan perfectamente dentro del esquema general de discontinuidad cultural que supone el Hierro II respecto al Orientalizante. 
En función de todo ello, es por lo que actualmente apostamos por una diferenciación cultural de lo «turdetano» frente a lo «túrdulo», cuya esencia y entidad parecen residir en la interacción de elementos de tradición orientalizante, cogoteños, íbero-turdetanos e incluso neopúnicos; interacción surgida justamente en los límites territoriales comunes entre La Meseta y el Guadalquivir. Quizá este mestizaje cultural constituyera también para los autores clásicos el argumento principal de diferenciación entre «turdetanos» y «túrdulos», reservando esta última denominación (que en sí misma no es más que una derivación de «turdetanos») para designar a los «turdetanos del interior». Sin embargo y como ya quedara planteado al comienzo de este trabajo, junto a las cuestiones estrictamente materiales precisamos concretar aún más otros aspectos menos tangibles como son la economía, los ritos y las costumbres religiosas para aproximarnos a la compleja realidad de éste o cualquier otro grupo humano.

En conclusión, el panorama poblacional que actualmente poseemos del sector extremeño de la Beturia de los túrdulos viene a corresponderse con el de un espacio con notables desequilibrios en su ocupación global. Como hemos tenido ocasión de comprobar, ésta parece ser más intensa en aquellos puntos de mayor valor estratégico, como son los vados del Guadiana, el Zújar y los principales puertos de su periferia. Sin duda alguna, dichos puntos debieron constituir en sí mismos auténticos núcleos de control del tráfico por este territorio, cuya orografía caminera ha debido ser un condicionante de primer orden en su dilatada historia de intercambios entre el Guadiana y el Guadalquivir. Por otra parte y como simple hipótesis de trabajo, planteamos que los relativos vacíos poblacionales que la investigación reciente está poniendo de manifiesto en las comarcas centrales de este amplio espacio han de valorarse dentro de un ciclo histórico prolongado y de un modo interrelacionado con el fin de Cancho Roano en torno al 400 a C. (con todo lo que ello representa) y el surgimiento de un foco sociocultural emergente como es la «Beturia Céltica». Fruto de ello pudo ser no sólo la coexistencia en el suroeste de Badajoz de tradiciones tecnológicas diversas (Hernández Carretero, 1993), sino también la difusión hacia este área túrdula de unas fórmulas de recuperación económica basadas en la potenciación de la explotación de los pastos y la metalurgia del hierro así como de otros aspectos materiales o ideológicos como son ciertas modas cerámicas o determinadas creencias religiosas propias del mundo meseteño. Pero, en nuestra opinión y con la prudencia obligada que imponen los argumentos de silencio o la valoración conjunta de esta zona con el foco minero de Almadén y el norte de Córdoba, la verdadera entidad de este espacio en el contexto global de la Beturia debió radicar en el control y canalización de los contactos con el Guadalquivir e incluso con el Levante, como parece derivarse de algunos de los aspectos tratados con anterioridad y de otros testimonios particulares recientemente estudiados en el Tajo Medio (Cabello Caja, e.p.)

Pero si interés muestra a primera vista la estructura general del poblamiento túrdulo, mucho más sugerente y definidor para este espacio nos resultan las novedades que introduce el contacto con el mundo romano. En este ámbito, quizá las aportaciones más relevantes sean las que ofrecen las excavaciones del ya citado poblado de Hornachuelos y el conjunto de fortificaciones ciclópeas que sólo en la comarca de la Serena superan el medio centenar (Ortiz Romero, 1991; Rodríguez y Ortiz, 1986 y 1989). De este modo, la entidad alcanzada por Hornachuelos en esta nueva etapa parece estar en estrecha relación con la política romana de relocalización y concentración de poblaciones indígenas en determinadas áreas o núcleos con el propósito de asegurar su control militar y rentabilizar al máximo la explotación de sus recursos. En este sentido, podemos concretar, por un lado, el carácter principal que pudo poseer el valle del Matachel como ruta militar en época republicana; $y$, por otro, el potencial agroganadero y especialmente minero (plomo argentífero) que debió convertir este asentamiento en un importante centro capitalizador de la metalurgia de esta zona, cumpliendo un papel paralelo al que poco tiempo después desarrollaría el Cabezo de Miróbriga en el valle del Zújar (Pastor y Pachón, 1991). Por otra parte y en relación a los recintos ciclópeos de La Serena, señalar que, a medida que se ha ido avanzando en su estudio, se han podido ir perfilando y 
concretando muchos aspectos relacionados con su función, filiación y cronología (Rodríguez y Ortiz, 1990). Especialmente sugerente se nos antoja su posible relación con la definición de una ruta fortificada que durante el siglo I a. C. (o incluso antes) ejerciera el papel de un verdadero limes al garantizar la seguridad y el control de este territorio frente a grupos céltico-lusitanos hostiles así como la explotación minera de esta comarca (Ortiz Romero, e.p.; Rodríguez Díaz, e.p.) Este último aspecto, como es de sobra conocido, mantiene directa conexión con la puesta en valor de otras zonas metalíferas próximas como Azuaga (Domergue, 1970) y el noroeste de Córdoba (Domergue, 1985 y 1987) a raíz de los conflictos bélicos de finales de la República. Precisamente, debido quizá al carácter militar y fronterizo que mantuvo esta zona durante tanto tiempo procesos integradores como su municipalización o su reorganización económica sufrieran un cierto retraso (Stylow, 1991).

\section{RECAPITULACIÓN}

Una valoración final sobre la Cuenca Media del Guadiana durante el Hierro II y la presencia inicial romana ha de subrayar necesariamente el carácter de frontera que ha definido a este espacio no sólo en estos siglos sino a lo largo de toda su historia. Posiblemente desde esa perspectiva sea mucho más fácil comprender que, tras la crisis del Orientalizante y en el confín septentrional de la Turdetania, surgiera a partir del 400 a C. el espacio socioeconómico y cultural que los autores clásicos identificaron con la Beturia. Como hemos tratado de exponer en las páginas anteriores, la realidad económica que subyace en este panorama general del Guadina Medio durante este período es la configuración de una nueva estrategia territorial basada en la explotación intensiva de los pastos y del hierro. Sin duda, el aspecto que hasta el momento mejor refleja dichas transformaciones es la relocalización mayoritaria de los asentamientos respecto a épocas anteriores. Éstos, a partir de ahora, se ubicarán-sin descuidar el control de los principales vados del Guadiana-en lugares elevados y especialmente próximos a los mejores pastos y a las más densas concentraciones férricas de la Baja Extremadura. Sin embargo, con la información arqueológica que hoy poseemos y las lógicas limitaciones que impone el desconocimiento de otros aspectos no estrictamente arqueológicos, resulta aún muy difícil aproximarse al estudio de los mecanismos reales que regularon dicho entramado económico y que, en definitiva, fueron los agentes responsables de las nuevas relaciones socioculturales que tienen como escenario este marco geográfico.

Pero en contra de lo que pudiera imaginarse, estas pautas socioeconómicas no se tradujeron en un paisaje cultural unitario y monovalente. En función de los contrastes comarcales de todo tipo que existen en esta región, comienzan a esbozarse dos zonas con sugerentes matices diferenciadores entre sí. Dichos ámbitos cada vez más parecen corresponderse con la dualidad étnica y geográfica que las fuentes contemplaron en este territorio: la Beturia Céltica y la Beturia Túrdula. Es evidente que no debió tratarse de espacios fronterizos en el más estricto sentido del término, sino tan sólo de dos áreas perfectamente interrelacionadas pero con ítems diversos que hoy por hoy se nos manifiestan con desigual intensidad en cada una de ellas. Aunque nuestro trabajo está todavía basado en un conocimiento diferencial del territorio e incluso en ciertos argumentos de silencio (con los riesgos que ello conlleva), todo parece indicar que el sector céltico de la Beturia constituyó un foco económico de primer orden que atrajo a grupos diversos de población. Éstos vivieron en pequeños núcleos fortificados, localizados generalmente en lugares no ocupados en épocas precedentes. Dichos asentamientos muestran una relación directa con la explotación del paisaje de dehesa que les rodea, el control de las cuencas de los principales ríos y, sobre todo, con el enorme potencial férrico de estas comarcas. A pesar de las múltiples interrogantes que hoy se mantienen sobre las costumbres funerarias y religiosas de estas gentes, la toponimia, la antroponimia y sus restos 
muebles ofrecen vínculos innegables con el mundo céltico peninsular. No obstante y según se desprende de los propios textos, su integración y fusión con los elementos autóctonos del Guadiana Medio no debió suponer ningún trauma. Desde el punto de vista estrictamente arqueológico, todo ello podría tener un claro reflejo en la filiación diversa de la tecnología recuperada en estos enclaves.

Por otro lado, el territorio badajocense integrado en la Beturia de los túrdulos ofrece un panorama poblacional más heterogéneo e incluso con áreas poco habitadas, si bien todo ello habrá de valorarse conjuntamente con las aportaciones que pueda ofrecer la mitad occidental de la provincia de Ciudad Real y el norte cordobés. En la interpretación de dicho paisaje quizá haya que valorar de un modo interrelacionado aspectos como el final definitivo del sistema socioeconómico representado en Cancho Roano y la consolidación paulatina de la propia Beturia Céltica como foco emergente. El control de los principales vados del Guadiana y de las rutas naturales hacia el Guadalquivir y/o La Meseta se configuran por ahora como factores principales de localización indígena en este territorio. En este sentido, podemos decir que nos encontramos ante un espacio abierto por naturaleza en el que, según se infiere de los restos materiales recuperados, se conjugan influjos cogoteños, turdetanos e incluso neopúnicos. Todo ello, a nuestro juicio, parece constituir la base cultural de lo túrdulo frente a lo puramente meridional o meseteño. Con la llegada de los romanos, este espacio potenció aún más su valor estratégico y por ende su carácter fronterizo, como se deduce de fundaciones militares como la de Hornachuelos, Medellín o la red de fortificaciones ciclópeas de La Serena. Sin embargo y como es de sobra conocido, las consecuencias culturales posteriores de esta nueva etapa se concretaron en la disgregación definitiva de sus seculares costumbres.

\section{BIBLIOGRAFÍA}

AA. VV. (1987-1): Iberos. Actas de las I Jornadas sobre el Mundo Ibérico. Jaén, 1985.

AA. VV. (1987-2): La minería en Extremadura. Mérida.

ABAD CASAL, L. (1987): «La Cultura Ibérica». Historia General de España y América, I-2. Madrid. pp. 171-223.

ABASOLO ÁLVAREZ, J. A. y RUIZ, I. (1979): «Un conjunto arqueológico de Ubierna. Contribución al estudio de la Edad del Hierro en la Meseta Norte». BSAA., XLV. pp. 168-188.

ABASOLO ÁLVAREZ, J. A.; RUIZ, y PÉREZ, F. (1983): «Castrojeriz, I. El vertedero de la Colegiata». Noticiario Arqueológico Hispánico, 17. pp. 191-319.

ALBERTOS FIRMAT, M. L. (1975): «Organizaciones suprafamiliares en la Hispania Antigua». Studia Archaelogica, 37.

ALMAGRO GORBEA, M. (1973): «Los Campos de Túmulos de Pajaroncillo (Cuenca). Aportación al estudio de los túmulos de la Península Ibérica». Excavaciones Arqueológicas en España, 83. Madrid. - (1976-78): «La iberización de las zonas orientales de la Meseta Sur». Ampurias, 38-40. pp. 93-156. - (1977): «El Bronce Final y el Período Orientalizante en Extremadura». BPH., XIV. Madrid.

- (1983): «Colonizzazione e acculturazione nella Penisola Iberica». Modes de contacts et processus de transformation dans les sociéteés anciennes. Pise-Roma. pp.429-461.

- (1989): «Arqueología e Historia Antigua. El proceso protoorientalizante y el inicio de los contactos de Tartessos con el Levante mediterráneo». Gerión. Anejos, II. Estudios sobre la Antigüedad en homenaje al Pfr. Santiago Montero Díaz. pp. 277-288.

- (1990): «Segunda Edad del Hierro. La celtización de la Península Ibérica». Historia de España, I. Ed. Planeta. Madrid. pp.554-562.

-(1994):: «Los Celtas en la Península Ibérica: origen y personalidad cultural». Los celtas: Hispania y Europa. 121 y ss. 
ALMAGRO GORBEA, M. y LORRIO ALVARADO, A. (1986): «El castro de Entrerríos (Badajoz)». Rev. de Estudios Extremeños.

- (1987): «La expansión céltica en la Península Ibérica: una aproximación cartográfica». I Simposium sobre los Celtíberos. Daroca, 1986. pp. 105-122.

ÁLVAREZ MARTÍNEZ, J. M. (1985): «El tiempo antiguo». Historia de Extremadura, I. Badajoz.

ÁLVAREZ S. DE BURUAGA, J. (1970): «Un exvoto de bronce a Ataecina-Proserpina en el Museo de Mérida». XI Congreso Nacional de Arqueología. Zaragoza. pp. 827-830.

ÁLVAREZ SANCHÍS, J. R. (1990): «Los verracos del Valle del Amblés (Avila): del análisis espacial a la interpretación socioeconómica». Trabajos de Prehistoria, 47. pp. 201-233.

ALVES DÍAS, M.; BEIRAO, C. M. e COELHO, L. (1970): «Duas necrópolis da Idade do Ferro no BaixoAlentejo: Ourique (Noticia preliminar». O Arqueólogo Portugués, Serie III, IV. pp. 175-219.

ARNAUD, J. e JUDICE GAMITO, T. (1974-77): «Cerámicas estamplhadas da Idade do Ferro no sul de Portugal. I.- Cabeça de Vaiamonte-Monforte». O Arqueólogo Portugués, VII-IX. pp. 165-200.

BALMORI, H. (1935): «Aaecina, Adaegina». Emerita, 3. pp. 214-224.

BARRIENTOS ALFAGEME, G. (1990): Geografía de Extremadura. Ed. Universitas. Badajoz.

BARRIO MARTÍN, J. (1988): Las cerámicas de la necrópolis de Las Erijuelas (Cuéllar, Segovia). Estudio de sus producciones cerámicas en el marco de la II Edad del Hierro en la Meseta Norte. Segovia.

BEIRAO, C. M. (1986): Une civilisation protohistorique du Sud de Portugal (1er. Age du Fer). París.

BEIRAO, C. M., TAVARES, C., SOARES, J. VARELA, M. y VARELA, R. (1985): «Depósito votivo de II Idade do Ferro de Garvao. Noticia da primera campanha de escavasoes». O Arqueólogo Portugués, 3. Serie IV. 45-135.

BELÉN DEAMOS, M. y ESCACENA CARRASCO, J. L. (1992): «Necrópolis ibéricas de Andalucía Occidental». Congreso de Arqueología Ibérica. Las Necrópolis. Madrid.

BERROCAL RANGEL, L. (1988): Excavacines en Capote (Beturia Céltica), I. Serie Nertobriguense, I. - (1989a): «Placas áureas de la Edad del Hierro en la Meseta Occidental. TP., 46. pp. 279-291.

- (1989b): «El asentamiento «céltico» del Castrejón de Capote». CuPAUAM., 16. 245-295.

- (1990): «Materiales cerámicos a mano de una necrópolis nertobriguense (EL Cantamento de la Pepina, Badajoz)». Necrópolis celtibéricas. Il Simposio sobre los Celtíberos. Zaragoza. 311-316.

- (1992): Los pueblos célticos del Suroeste de la Península Ibérica. Madrid.

BLÁNQUEZ PÉREZ, J. J. (1990): La formación del Mundo Ibérico en el Sureste de la Meseta. (Estudio arqueológico de las necrópolis ibéricas de la provincia de Albacete). Albacete.

BLASCO BOSQUED, C. (1987): «La España celtibérica: La Segunda Edad del Hierro en la Meseta». Historia General de España y América, I-2. Madrid. 297-327.

- (1989): «El fenómeno céltico». Los celtas en el Valle Medio del Ebro. Zaragoza. 15-38.

BLÁZQUEZ MARTÍNEZ, J. M. (1957): «La economía ganadera de la España prerromana a la luz de las fuentes literarias griegas y romanas». Emérita, XXV.pp. 159-184.

- (1962): «Bronces prerromanos del Museo Arqueológico de Cáceres». Archivo Español de Arqueología, $X X X V$..pp. 129-131.

- (1968): «Economía de los pueblos prerromanos del área no ibérica hasta la época de Augusto». Estudios de economía antigua de la Península Ibérica. Barcelona. pp. 191-269.

- (1975): «Cástulo I». AAH., 8. Madrid.

- (1983): Religiones Prerromanas (Primitivas Religiones Ibéricas). Madrid.

CABALLERO ZOREDA, L. y ROSCO MADRUGA, J. (1988): «Iglesia visigoda de Santa Lucía del Trampal, Alcuéscar (Cáceres). Primera campaña de trabajos arqueológicos, 1983-4». Extremadura Arqueológica, I. pp. 231-249 (en particular, 240-241). 
CABELLO CAJA, R. (E.p.): «Las cerámicas pintadas de la II Edad del Hierro en el Valle Medio del Tajo». Norba, 11-12.

CABRÉ AGUILÓ J. (1932): «Excavaciones de Las Cogotas. Cardeñosa (Avila). II, La Necrópolis». MJSEA., 120.

CABRÉ, J., CABRÉ DE MORáN, E. y MOLINERO, A. (1950): «El castro y necrópolis del Hierro céltico de Chamartín de la Sierra (Avila)». Acta Arqueológica Hispánica, $V$.

CANTO DE GREGORIO, A. (e.p.): «La Beturia Férrica: un problema de transmisión pliniana (y corolario para la Tabula Siarensis)». Etudes Céltiques.

CARRASCO MARTIN, M. J. (1991): «Excavaciones de urgencia en el Castillo de la Morería (Jerez de los Caballeros, Badajoz)». Extremadura Arqueológica, II. pp. 559-577.

CASTAÑOS UGARTE, P. M. (1987): «Estudio de los restos óseos del poblado prerromano de Los Castillejos de Fuente de Cantos (Badajoz)». En RODRÍGUEZ DÍAZ, A.: El poblamiento prerromano en la Baja Extremadura. Tesis Doctoral. Inédita. Cáceres.

- (1991a): «Estudio de los restos óseos del yacimiento de la Ermita de Belén (Zafra, Badajoz)». En RODRÍGUEZ DÍAZ, A.: La Ermita de Belén (Zafra, Badajoz). Campaña 1987. Mérida. pp. 247-258. - (199lb): «Animales domésticos y salvajes en Extremadura. Origen y evolución». Rev. de Estudios Extremeños, XLVII-I.pp. 9-66.

CASTIELLA RODRÍGUEZ, A. (1977): «La Edad del Hierro en Navarra y Rioja». Excavaciones en Navarra, VIII. Pamplona.

CUADRADO DÍAZ, E. (1953): «Materiales ibéricos: cerámica roja de procedencia incierta». Zephyrus, IV

- (1969): «Origen y desarrollo de la cerámica de barniz rojo en el mundo tartésico». I Symposium de Prehistoria Peninsular. 257-291.

- (1981): «Las necrópolis peninsulares en la Baja Epoca de la Cultura Ibérica». La Baja Epoca de la Cultura lbérica. Madrid, 1979. 51-72.

- (1987): «La necrópolis ibérica de El Cigarralejo (Mula, Murcia». BPH., XXIII. Madrid.

CUADRADO DE ISASA, F. (1970): «Formas nuevas de la cerámica de barniz rojo». XI CNA. Zaragoza.

DEL AMO Y DE LA HERA, M. (1978): «El Castañuelo. Un poblado céltico en la provincia de Huelva». Huelva Arqueológica, IV. 299-340.

DOMERGUE, C. (1970): «Un témoignagne sur l'industrie minière et métallurgique du plomb dans la région d'Azuaga (Badajoz) pendant la guerre de Sertorius». XIV CNA. pp. 608-625

- (1985): «Algunos aspectos de la explotación de las minas de la Hispania en la época republicana». Pyrenae. Crónica Arqueológica. pp. 91-96.

- (1987): Catalogue des mines et fonderies antiques de la Péninsule Ibérique. Série Archéologique, VIII. Madrid. 2 vols.

DOMÍNGUEZ DE LA CONCHA, M. C. y GARCÍA BLANCO, J. (1991): «La Tabla de las Cañas (Capilla, Badajoz). Apuntes preliminares». Extremadura Arqueológica, II. 235-245.

DOMÍNGUEZ MONEDERO, A. (1983): «Los términos Iberia e Iberos en las fuentes grecolatinas: Estudio acerca de su origen y ámbito de aplicación». Lucentum, II. pp. 203-224.

ENRÍQUEZ NAVASCUÉS, J. J. (1988): «Algunas cerámicas decoradas del Castillo de Alange». Homenaje a Samuel de los Santos.

ENRÍQUEZ NA VASCUÉS, J. J. y RODRÍGUEZ DÍAZ, A. (1985): Las piezas de oro de Segura de León y su entorno arqueológico. Mérida.

- (1988): «Campaña de urgencia en la Sierra de la Martela (Segura de León, Badajoz)». Extr. Arq., I. 
ESCACENA CARRASCO, J. L. (1986): Cerámicas a torno pintadas andaluzas de la Segunda Edad del Hierro. Tesis Doctoral. Ed. microfichas. Universidad de Sevilla. Sevilla.

- (1987): «El poblamiento ibérico en el Bajo Guadalquivir». Iberos. Actas sobre las I Jornadas sobre Mundo Ibérico. Jaén, 1985. pp. 273-298.

- (1989): «Los turdetanos o la recuperación de la identidad perdida». Tartessos. Arqueología protohistórica del Bajo Guadalquivir. Sabadell. pp. 433-476.

FERNÁNDEZCORRALES, J. M.; SAUCEDA PIZARRO, M. I. y RODRÍGUEZ DÍAZ, A. (1988): «Los poblados calcolítico y prerromano de Los Castillejos (Fuente de Cantos, Badajoz)». Extremadura Arqueológica, $I$.

FERNÁNDEZ GÓMEZ, F. (1986): Excavaciones arqueológicas en el Raso de Candeleda, I y II. Ávila. FERNÁNDEZ JURADO, J. (1987): «El poblamiento ibérico en Huelva». Iberos. Actas sobre las I Jornadas sobre Mundo Ibérico. Jaén, 1985. pp. 315-326.

FERNÁNDEZ OCHOA, C. y CABALLERO KLINK, A. (1986): «El horizonte histórico de La Bienvenida y su posible identificación con Sisapo». I Congreso de Historia de Castilla-La Mancha. C. Real.

FERNÁNDEZ RODRÍGUEZ, M. D. (1987): Alarcos. La cerámica de barniz rojo del cerro de Alarcos. Ciudad Real.

FERREIRA DA SILVA, A.C. e VARELA GOMES, M (1992): Protohistórica de Portugal. Lisboa.

GARCÍA CANO, J. M. e INIESTA SANMARTÍN, A. (1983): «Aproximación a la cerámica de barniz rojo ibero-tartéssica en la regiónde Murcia». XVI CNA. Zaragoza. 561-572.

GARCÍA Y BELLIDO, A. (1945): España y los españoles hace dos mil años. Madrid, 1986. $9^{\mathrm{a}}$. - (1947): La España del siglo I de nuestra Era (según P. Mela y C. Plinio). Madrid, 1978. $3^{\mathrm{a}}$.

GARCÍA Y BELLIDO, M.P. (1991): «Las religiones orientales en la Península Ibérica: documentos numismáticos», I. AEspA. 64. 37-81.

GARCÍA IGLESIAS, L. (1971): «La Beturia, un problema geográfico de la Hispania Antigua». Archivo Español de Arqueología, 44. 86-108.

GARCÍA MORA, F. (1991): Un episodio de la Hispania Republicana: la guerra de Sertorio. Granada.

GARCÍA MORENO, L. A. (1989): «Turdetanos, túrdulos y tartessios. Una hipótesis». Gerión. Anejos II. Estudios sobre la Antigüedad en homenaje al Pfr. Santiago Montero Díaz. pp. 289-294.

HERNÁNDEZ CARRETERO, A. (1993): Relaciones culturales durante la Segunda Edad del Hierro en el Valle Medio del Guadiana. I, La cerámica gris. Tesis de Licenciatura. Inédita. Cáceres.

JIMÉNEZ ÁVILA, F. J. (1990): Estudio arqueológico del poblado de Hornachuelos (Ribera del Fresno, Badajoz) y su entorno. Tesis de Licenciatura. Inédita. Cáceres.

JUDICE GAMITO, T. (1981): «A propósito do castro de Segovia (Elvas). Resistencia a Roma no Sudoeste peninsular».I 29. 32-43.

LÓPEZ MELERO, R. (1986): «Nueva evidencia sobre el culto de Ategina: el epígrafe de Bienvenida». Manifestaciones religiosas en la Lusitania. Cáceres. pp. 83-112.

LÓPEZ PALOMO, L. A. (1987): «Iberos y celtas en la penillanura de Los Pedroches (Córdoba)». Rev. Arqueología, 69. 37-45.

LORRIO ALVARADO, A. (1988-89): «Cerámica gris orientalizante de la necrópolis de Medellín (Badajoz)». Zephyrus, XLI-XLII. pp. 283-314.

MAIA, M. (1985): «Celtici e turduli nas fontes clássicas». Actas III Coloquio sobre lenguas y culturas paleohispánicas. Lisboa, 1980. Salamanca. pp. 165-177.

MALUQUER DE MOTES, J. (1981): «EL Santuario protohistórico de Zalamea de la Serena (Badajoz)». En MALUQUER DE MOTES, J. y AUBET SEMMLER, M. E.: Andalucía y Extremadura. PIP. Barcelona. pp. 225-409. 
- (1982): «Los pueblos de la España céltica». Historia de España dirigida por R. Menéndez Pidal, I3. $4^{a}$. Madrid, 1954. $1^{\text {a }}$. pp. 5-305.

MALUQUER DE MOTES, J., CELESTINO PÉREZ, S., GARCÍA, F. y MUNILLA, G. (1986): El Santuario protohistórico de Zalamea de la Serena, Badajoz, III. 1983-1986. Barcelona.

MARTÍN VALLS, R. (1985): «Segunda Edad del Hierro. Las culturas prerromanas». La Prehistoria del Valle del Duero, 1. Valladolid. pp. 104-131.

- (1986-87): «La Segunda Edad del Hierro: consideraciones sobre su periodización». Zephyrus, $X X X I X-X L$. pp. 59-86.

MURILLO REDONDO, J. F. (1993): «Poblamiento y minería en el norte de la provincia de Córdoba». I Coloquio $H^{a}$ Andalucía. Córdoba, 265 ss.

OLMOS ROMERA, R. (1977): «El Sileno Simposiasta de Capilla (Badajoz)». TP., 34. 371-388.

ORTIZ ROMERO, P. (1991): «Excavaciones y sondeos en los recintos de tipo torre de La Serena». Extremadura Arqueológica, II. pp.301-317.

-(e.p.): «Los recintos-torre de La Serena. Excavaciones en Hijovejo(Quintana de la Serena, Badajoz)».

ORTIZ ROMERO, P. y RODRÍGUEZ DÍAZ, A.: (1989): «Problemática general en torno a los recintostorre de La Serena, Badajoz». XIX Congreso Nacional de Arqueología. Castellón-Zaragoza.

PASTOR MUÑOZ, M. y PACHÓN ROMERO, J. A. (1991): «Excavación arqueológica en Miróbriga: campañas 1987-1988». Extremadura Arqueológica, II. pp. 347-360.

PEREIRA SIESO, J. (1988): «La cerámica ibérica pintada de la cuenca del Guadalquivir. I, Propuesta de clasificación». Trabajos de Prehistoria, 45. 143-173.

- (1989): «La cerámica ibérica pintada de la cuenca del Guadalquivir. II, Conclusiones». Trabajos de Prehistoria, 46. 149-159.

PÉREZ MACÍAS, A. (1987): Carta Arqueológica de los Picos de Aroche. Huelva.

- (1990): Castañuelo, los orígenez de la Baeturia Céltica. Museo Arqueológico de Huelva. Huelva. RODRÍGUEZ DÍAZ, A. (1986): Arqueología de Tierra de Barros. Mérida.

- (1987): El poblamiento prerromano en la Baja Extremadura. Tesis Doctoral. Inédita. Cáceres.

- (1989): «La Segunda Edad del Hierro en la Baja Extremadura: problemática y perspectivas en torno al poblamiento». Saguntum, 22. 165-224.

- (1990): «Continuidad y ruptura cultural durante la Segunda Edad del Hierro en Extremadura». La Cultura Tartésica y Extremadura. Mérida. 127-162.

- (1991a): La Ermita de Belén (Zafra, Badajoz). Campaña de 1987. Mérida.

- (1991b): «Proyecto Hornachuelos (Ribera del Fresno, Badajoz): 1986-1990». I Jornadas de

Prehistoria y Arqueología en Extremadura (1986-1990).Extremadura Arqueológica, II. MéridaCáceres. pp. 283-300.

-(E.p.)«Algunas reflexiones sobre el fin de Tartessos en el Valle Medio del Guadiana: la crisis del 400 a C. y el desarrollo de la Beturia» CUPAUAM, 20.

RODRÍGUEZ DÍAZ, A. y BERROCAL RANGEL, L. (1988): «Materiales cerámicos de la Segunda Edad del Hierro del Cantamento de la Pepina (Fregenal de la Sierra, Badajoz)». CuPAUAM., 15. 215-252.

RODRÍGUEZ DÍAZ, A. e IÑESTA MENA, J. (1984): «Las Dehesillas, un poblado prerromano en el término municipal de Higuera de Llerena, Badajoz)». Norba, 5. pp. 17-28.

RODRÍGUEZ DÍAZ, A. y ORTIZ ROMERO, P. (1986): «Avance de la primera campaña de excavación en el recinto-torre de Hijovejo (Quintana de la Serena, Badajoz). El sondeo núm. 2». Norba, 7. pp. 2541.

- (1990): «Poblamiento prerromano y recintos ciclópeos de La Serena, Badajoz». CuPAUAM., 17. 
SACRISTÁN DE LAMA, J. D. (1986): La Edad del Hierro en el Valle Medio del Duero. Rauda (Roa, Burgos). Valladolid.

SCHÜLE, W. (1969): Die Meseta-Kulturen der Iberischen Halbinsel. Berlín.

STYLOW, A. U. (1991): «El municipium Flavium V (...) de Azuaga (Badajoz) y la municipalización de la Baeturia Turdulorum». Studia Histórica, IX. 11-27.

UNTERMANN, J. (1965): «Elementos para un Atlas Antroponímico de la Hispania Antigua». BPH., VIII. Madrid.

VAQUERIZO GIL, D. (1986): «Indigenismo y Romanización en la Siberia Extremeña». Rev. Arqueología, 58. 10-18.

- (1988-89): «Ensayo de sistematización de la cerámica ibérica procedente de las necrópolis de Almedinilla, Córdoba». Lucentum, VIII-VIII. 103-132.

VIANA, A. y DÍAS DE DEUS, A. (1950): «Necrópolis céltico-romanas del concejo de Elvas (Portugal)». Archivo Español de Arqueología, XXIII. pp. 229-253.

WATTENBERG, F. (1963): «Las cerámicas indígenas de Numancia». BPH., IV. Madrid. - (1978): Estratigrafía de los cenizales de Simancas (Valladolid). Valladolid. 

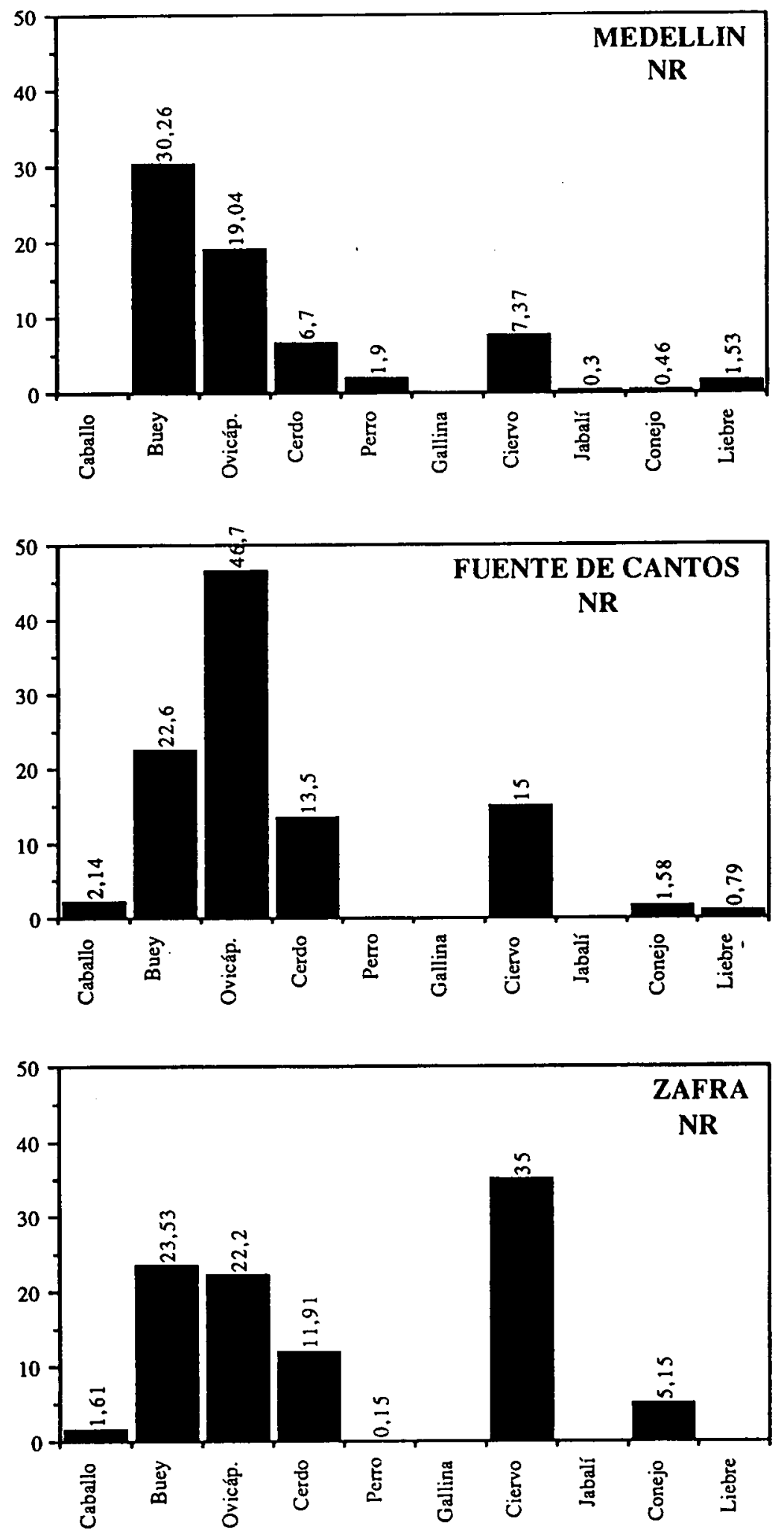

GRAFICA 1 

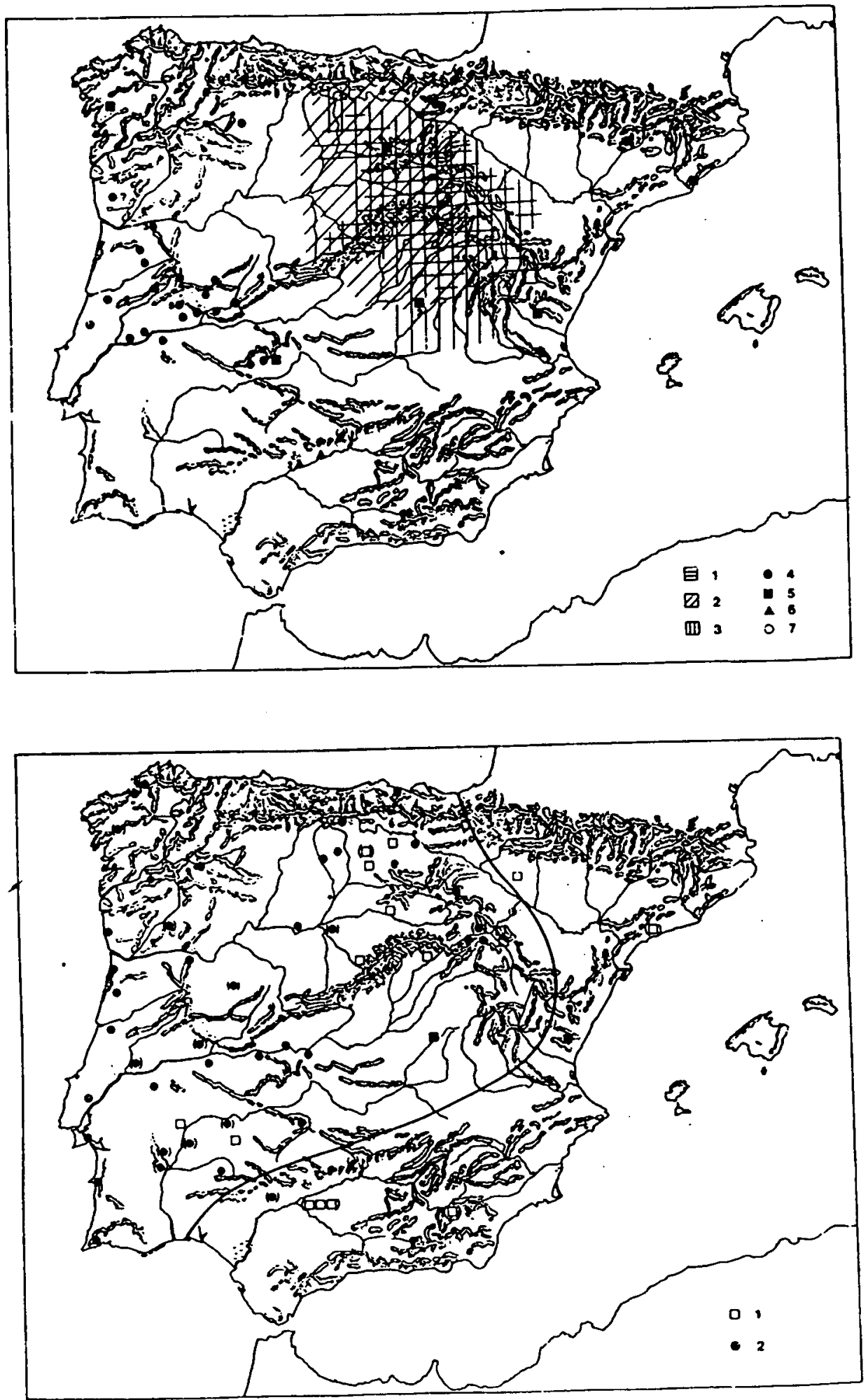

FIGURA 1. Area lingüística del celtibérico y toponimia en Seg- y en -briga, según diversos autores (Almagro Gorbea y Lorrio Alvarado, 1987). 


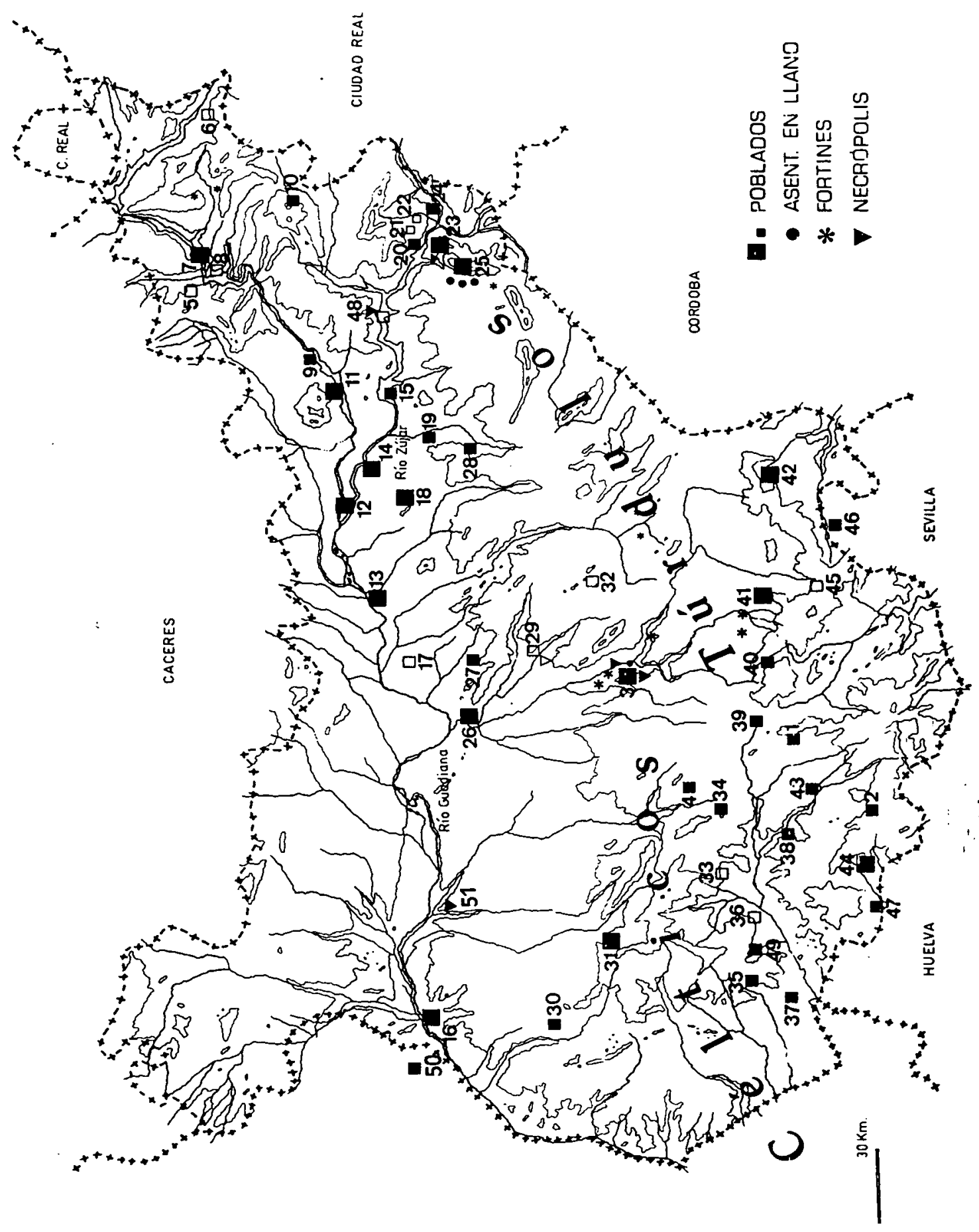

FIGURA 2. Poblamiento prerromano en el sector extremeño de la Cuenca Media del Guadiana. 

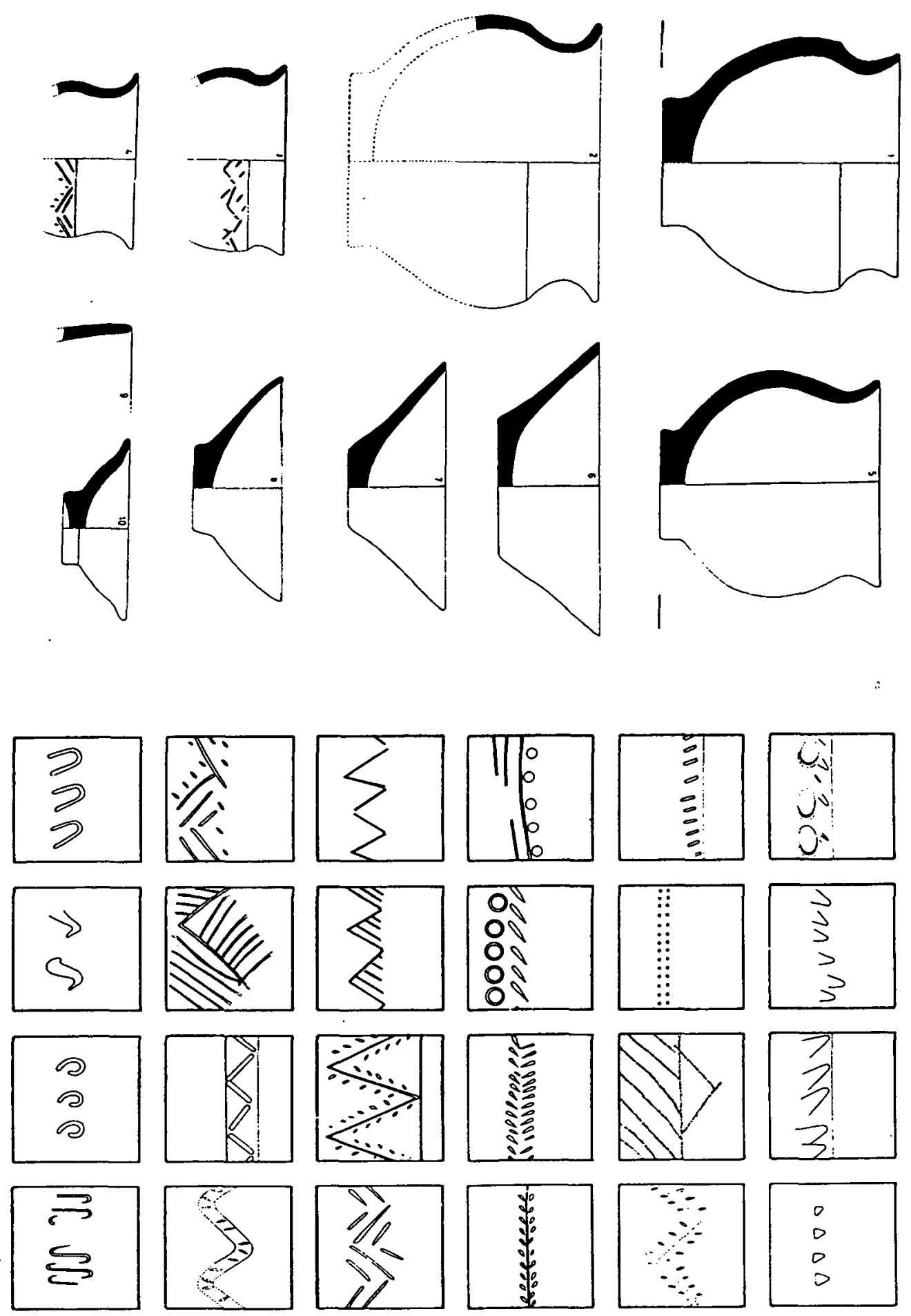

FIGURA 3. Cerámicas a mano del poblado de la Ermita de Belén (Zafra, Badajoz). Formas y motivos decorativos 


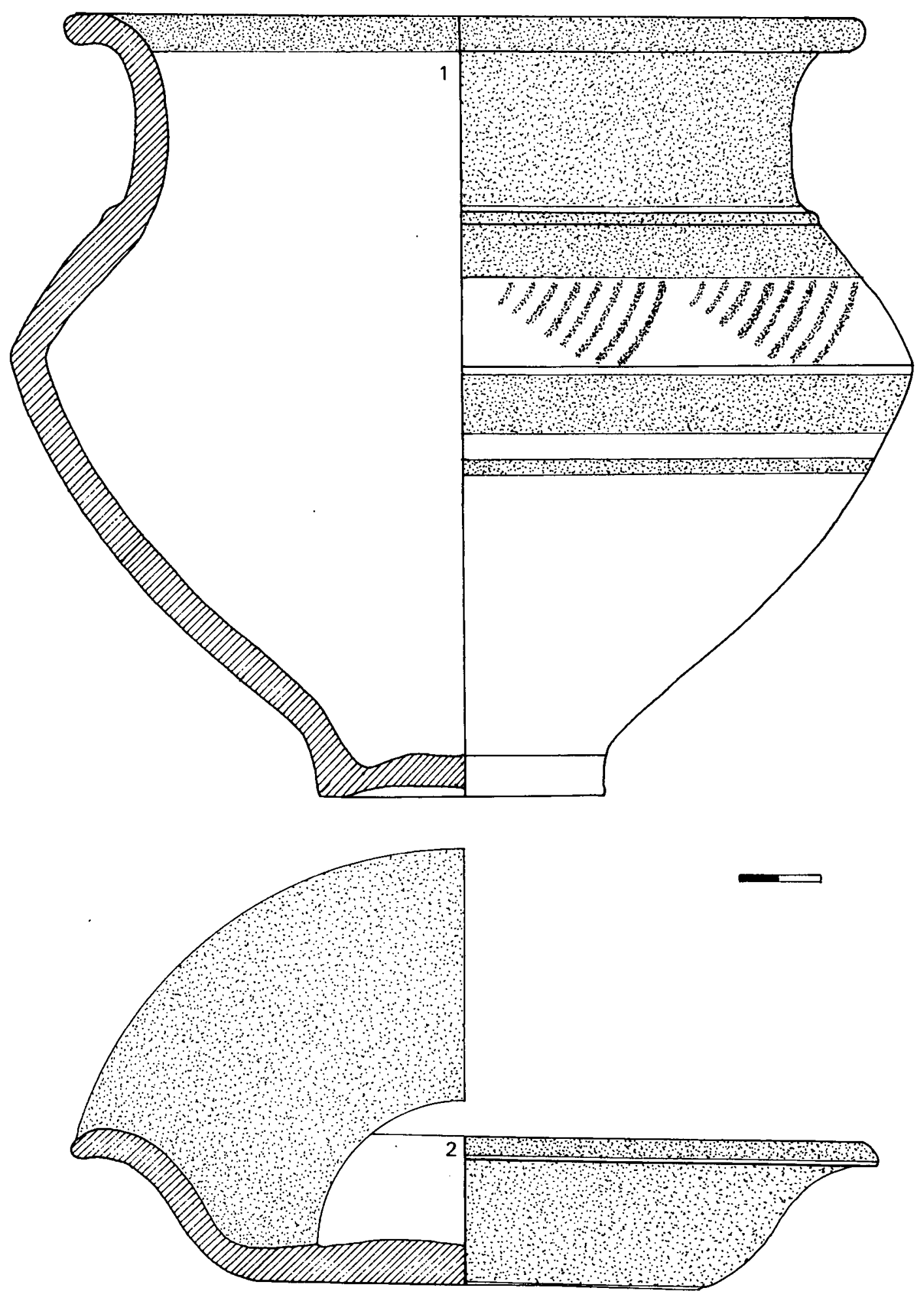

FIGURA 4. Ajuar funerario de Lobón (Badajoz). 


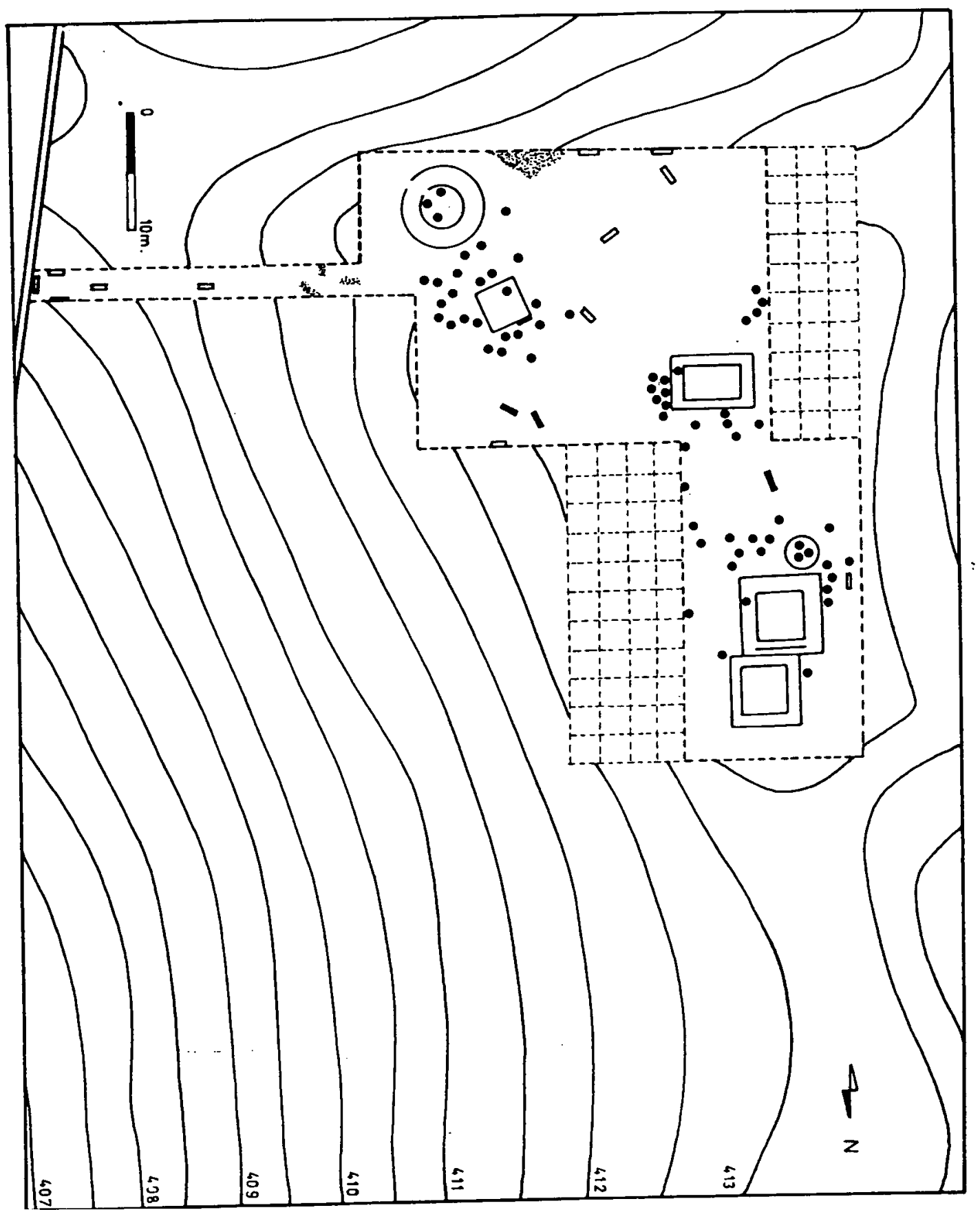

FIGURA 5. Planta-croquis de la necrópolis de Hornachuelos (campañas 1986-1992). 

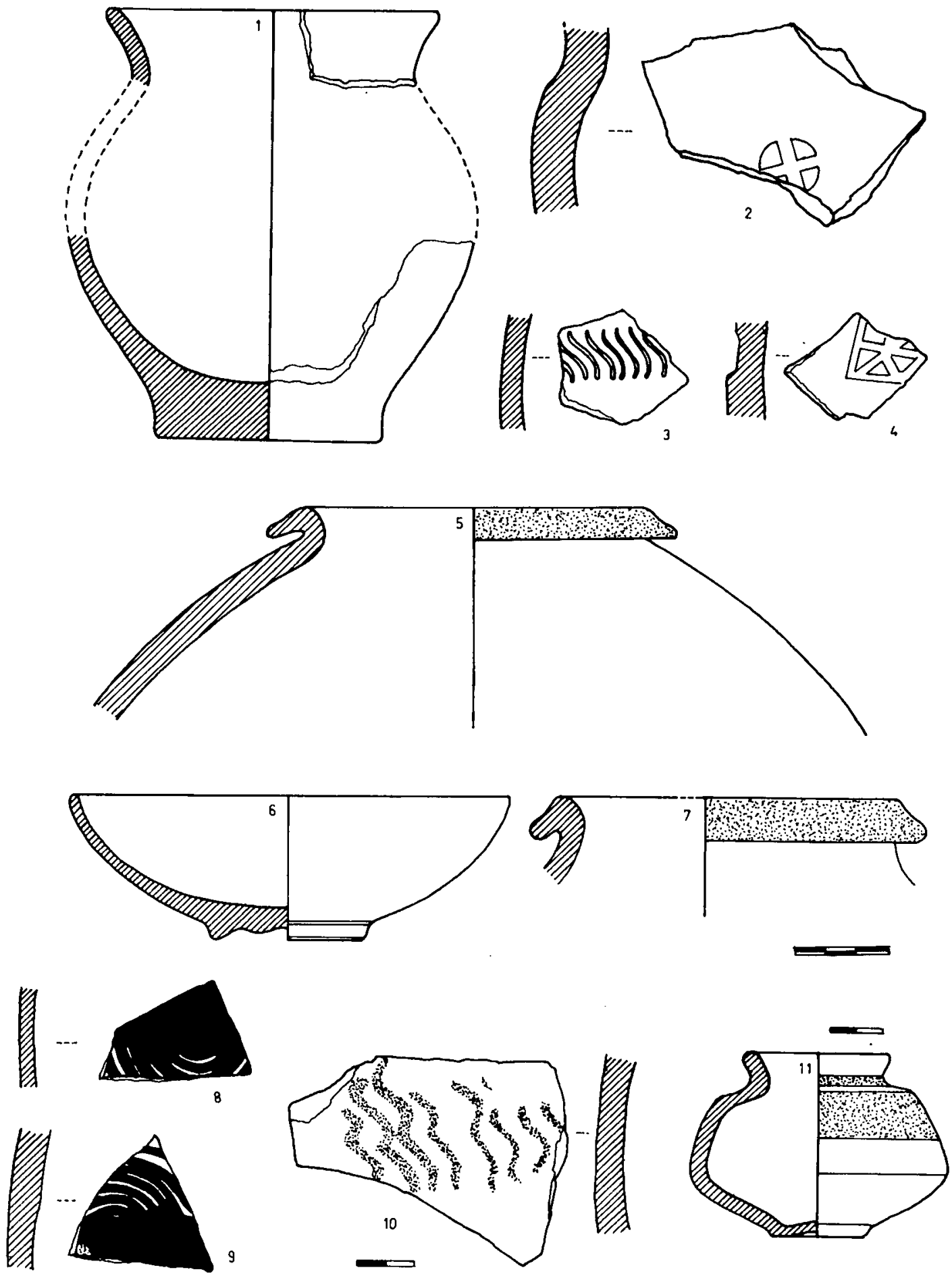

FIGURA 6. 1-9, Tabla de las Cañas (s. Domínguez y García, 1991); 10, Magacela; 11, Hornachuelos (necróp.) 